\title{
EFFECT OF VOLTAGE IN ELECTRO- HYDROLYTIC PRE-TREATMENT ON ANAEROBIC DIGESTION PERIOD
}

Shubham Bhatt

Student,

Dept of Biotechnology,

UCALS, Uttaranchal

University, Dehradun
Saurabh Nishad

Student,

Dept of Biotechnology,

UCALS, Uttaranchal

University, Dehradun

Abstract - Anaerobic digestion is well known and well developed technology applied for bioenergy production from different types of feedstock like animal manure, sewage sludge, agricultural residue, industrial waste etc. These different types of substrate are having high content of biodegradable material or organics which make this process an ideal biomass for anaerobic digestion process. Due to the natural intractable structure of lignocellulose biomass towards microbial or enzymatic deconstruction, pre-treatment is necessary to make the celluloses open to enzymatic hydrolysis for fermentation and anaerobic digestions. In recent years, there has been improved concern in pretreatment of lignocellulose biomass and waste for anaerobic digestion. This study was also focussed on the pre-treatment of lignocellosic biomass. In this research, the yield of biogas at $50 \mathrm{~V}$ was found to be $90.4 \%, 100 \mathrm{~V}$ was 83.1 respectively; whereas, without electro-hydrolysis $76.2 \%$ was observed. Moreover, the pretreated biomass gets stabilized at 15th day, but it took more than 18 days for the control or untreated biomass to get stabilize.

Keywords - Anaerobic digestion, lignocellulose, Electrohydrolytic, Rice Husk

\section{INTRODUCTION}

An anaerobic digestion is well developed technology widely applied for bioenergy production from the sewage sludge, animal manure, agricultural residue, industrial sludge etc. This substrate has high levels of biodegradable organics make it an ideal feedstock for anaerobic digestion. Due to the continuous production in the industrial level, there is a huge accumulation of waste especially in sugar mills; the huge quantity of bagasse as residue was produced.

The lignocellulose biomass is mainly consists of cellulose, hemicellulose, and lignin. Due to the natural intractable structure of lignocellulose biomass towards microbial or enzymatic deconstruction, pre-treatment is necessary to make the celluloses open to enzymatic hydrolysis for

Utkarsh Singh

Student,

Dept of Biotechnology,

UCALS, Uttaranchal

University, Dehradun
Dr. Rohit Sharma

Assistant Professor, Dept of Biotechnology, UCALS, Uttaranchal University, Dehradun

fermentation and anaerobic digestions. In recent years, there has been improved concern in pretreatment of lignocellulose biomass and waste for anaerobic digestion, Elliot et al. (2007). The several structural and compositional properties of lignocellulosic content render it resistant to biodegradation. Even though there has been an extensive research on the effect of pretreatment, the correlation between the degradability of lignocellulose material, the structural and compositional properties remains unclear and contradictory.

Use of lignocellulosic biomass for value-added products Lignocellulosic biomass is having potential as renewable resource which is present in plant cell and can be utilize directly for the production of energy products which can be used for a various purposes. The effect of hydrolysis of lignocellulosic biomass is shown in Figure 1.

Starch, Lignocellulose

Hydrolysis

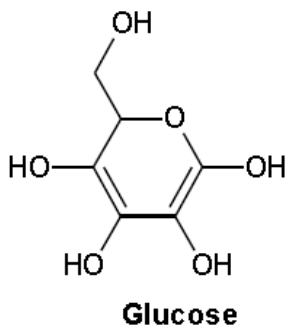

Fig. 1. Effect of hydrolysis of lignocellulosic biomass [2]

But, it is essential to break the three dimensional structure of polymer which is present in biomass into the simpler composites for gaining optimized advantage in various form of valuable products. The different forms of value added products from lignocellulosic biomass are shown in Figure 5 .

Elliot et al. (2012) and $\mathrm{Hu}$ et al. (2016) concluded that hydrolysis of biomass is the rate-limiting stage during 
anaerobic digestion which require pretreatment to get fasten. To accelerate the hydrolysis step, a novel electrohydrolysis pretreatment was considered. Based on literature known so for, an electrohydrolysis pretreatment has been studied first to improve the hydrolysis stage in anaerobic digestion of lignocellulose waste material, Updegraff (1969). Electrohydrolysis is the process of passing direct current (DC) through an ionic substance to solubilize the organic matter by breaking the bonds between polymers induced by application of current through electrodes, Varghese et al. (2014) and Wang et al. (2005). Electrodes when connected to DC one becomes positively charged electrode and another becomes negatively charged electrode. This initiates the movement of electrolyte towards electrodes i.e., positive ions move to cathode and negative ions move to anode.

The principle of electrohydrolysis pretreatment relies on electrophoresis, ohmic heating and electroosmosis resulting in the disintegration of particles and microbial cell lysis, Yuan et al. (2011).The electrophoresis is the process in which shifting of ions relative to a static phase depending on its electrical charge and molecular size. The process in which thermal energy is generated by passing electric current through organic materials is known as ohmic heating. The motion of solid particles suspended in a liquid, under the influence of an electrical field is known as electroosmosis. This process significantly reduces the HRT for biomethane production, Zhen et al. (2014).

\section{MATERIAL AND METHODOLOGY}

\section{A. Biomass source and characterization-}

Rice husk was collected from local market of Dehradun, Uttarakhand, India. This was then milled and screened to get particles with diameters smaller than $0.35 \mathrm{~mm}$. The powders were dried in an oven at $115{ }^{\circ} \mathrm{C}$ for $24 \mathrm{~h}$ and then kept in a desiccator at room temperature before further use. This feedstock is characterized by conducting proximate and ultimate analysis. The proximate analysis of sugarcane bagasse was analysed by ASTM and elements analysis (CHNSO) was determined by a Flash 2000 CHNS/O Organic Elemental Analyser (Thermo Scientific). Table 1 shows the proximate and ultimate analysis of biomass.

Table - 1 Proximate and Ultimate analysis of sugarcane bagasse

Weight \% (on air dried basis)

\begin{tabular}{ccccc}
\hline Moisture content & $\begin{array}{c}\text { Volatile } \\
\text { matter }\end{array}$ & Ash content & $\begin{array}{c}\text { Fixed } \\
\text { Carbon }\end{array}$ \\
16.5 & 56.4 & 3.9 & 23.2 \\
\hline \multicolumn{5}{c}{ Elemental composition (on dry basis) in wt \% } \\
\hline Carbon & Hydrogen & Nitrogen & Sulphur & Oxygen \\
43.6 & 13.6 & 18.9 & 0.5 & 23.4 \\
\hline
\end{tabular}

Cow dung collected from farm was used as the inoculum for the batch study. Table 2 shows the initial chemical characterization of inoculum.

Table - 2 Chemical characterization of cattle manure

\begin{tabular}{|c|c|}
\hline \multicolumn{2}{|c|}{ The initial chemical characterization of cow dung } \\
\hline Moisture content (\%) & 69.73 \\
\hline Total solid (TS) (\%) & 25.27 \\
\hline Volatile solid (VS) (\%) & 15.5 \\
\hline pH & 7.55 \\
\hline
\end{tabular}

\section{B. Experimental set up}

Electrohydrolysis pretreatment setup consists of cylindrical plastic feed tank (10 cm diameter and $30 \mathrm{~cm}$ height), DC power generator, mechanical stirrer with RPM regulator, multimeter, ammeter and tachometer. The feed tank was half filled with biomass in the ratio of 1:2 of distilled water to get slurry form. As biomass contain high total solid content, three part of water is added in order to make slurry condition to avoid clogging and also to provide enough passage way for DC. With the help of graphite electrode DC is supplied to the sample kept in the plastic tank. Two graphite electrode as cathode and anode are half immersed into the sample, placed at a distance without touching flash mixture and wall of the reaction tank.

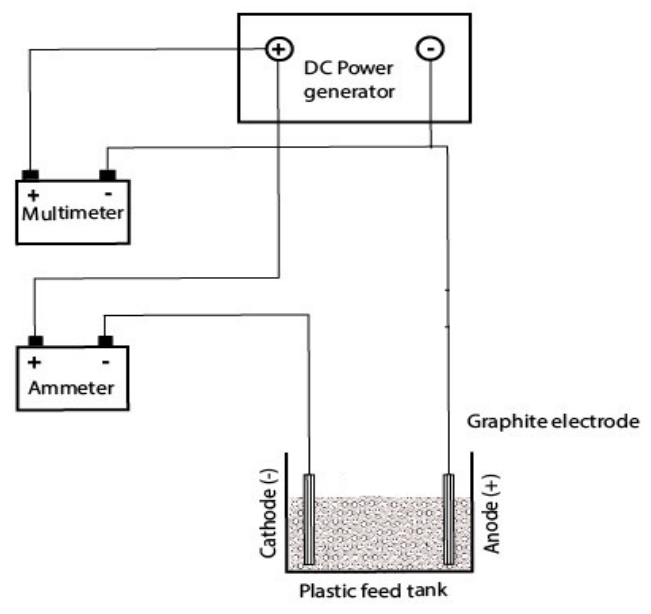

Fig. 2. Block diagram of electro-hydrolysis techniques

For electrohydrolysis pretreatment study, $400 \mathrm{~g}$ of biomass is added to $800 \mathrm{~mL}$ of distilled water and mix properly to get slurry form. The samples kept outside without any treatment is used as the control. 


\section{RESULT AND DISCUSSION}

\section{A. Volume of Biogas}

Effect of different voltage of current was observed in experiment 1 and experiment 2. The amount of biogas produced, was observes on a regular interval with the help of water displacement method. The data of the water displacement method recorded annually, is given in the table below-

Table - 3 Volume of biogas (in $\mathrm{ml}$ ) produce at different voltage of electo-hydrolysis

\begin{tabular}{|c|c|c|c|}
\hline $\begin{array}{c}\text { No. of } \\
\text { Days }\end{array}$ & $\mathbf{1 0 0 ~ V}$ & $\mathbf{5 0 ~ V}$ & $\begin{array}{c}\text { Control (without } \\
\text { electro-hydrolysis) }\end{array}$ \\
\hline Day 1 & 15 & 10 & 10 \\
\hline Day 3 & 63 & 26 & 16 \\
\hline Day 5 & 71 & 80 & 30 \\
\hline Day 7 & 155 & 66 & 51 \\
\hline Day 9 & 80 & 154 & 66 \\
\hline Day 11 & 20 & 10 & 60 \\
\hline Day 13 & 7 & 8 & 55 \\
\hline Day 15 & - & - & 38 \\
\hline Day 18 & - & - & 17 \\
\hline
\end{tabular}

The pretreated biomass gets stabilized at $15^{\text {th }}$ day, but control or untreated biomass took more than 18 days to stabilize. This is due to reduction in hydrolysis stage of biogas production. Electro-hydrolysis degrades complex materials in simpler ones which reduces the Hydro Retention Time (HRT) for biogas production.

\section{B. Yield of Biogas}

The yield of biogas in experiment at $50 \mathrm{~V}$ and experiment 100 was observed. The yield in experiment at $100 \mathrm{~V} 91.3$ $\%$, experiment at $50 \mathrm{~V}$ is $78.6 \%$ whereas without electrohydrolysis is $76.2 \%$, was found. Moreover, the pretreated biomass gets stabilized at $15^{\text {th }}$ day, but it took more than 18 days for the control or untreated biomass to get stabilize.

\section{IV.CONCLUSION}

The innovative study shown that electro-hydrolysis pretreatment has significant effect on the degradation of lignocellulose biomass by improving the hydrolysis stage of anaerobic digestion process.

Pretreated biomass produced $70 \%$ of biogas at $6^{\text {th }}$ days of production period in $100 \mathrm{~V}$ and $50 \mathrm{~V}$, which took 12 days by untreated biomass to get stabilized with $60 \%$ of biogas produced. This shows the reduction in HRT from 12 days to 6 days due to reduction in hydrolysis stage of biogas production process.

It was concluded that organic and inorganic materials in biomass were well solubilized at $100 \mathrm{~V}$ for 30 minutes in electro-hydrolysis pre-treatment. This study revealed that anaerobic digestion process can be improved through electro-hydrolysis pre-treatment at $100 \mathrm{~V}$ for 30 minutes which produced $90 \%$ biogas yield as compare to untreated sample of $76 \%$ with reduced HRT.

\section{REFERENCE}

[1] Elliot A. and Mahmood T. (2007) Pretreatment technologies for advancing anaerobic digestion of pulp and paper biotreatment residues. in Water Res., (pp. 4273-4286).

[2] Elliott A. and Mahmood T. (2012). Comparison of mechanical pretreatment methods for the enhancement of anaerobic digestion of pulp and paper waste activated sludge in Water Environ. Res. (pp. 497-505).

[3] Hu Y., Hao X., Wang J. and Cao Y. (2016). Enhancing anaerobic digestion of lignocellulosic materials in excess sludge by bioaugmentation and pre-treatment in Waste Manage. (pp. 55-63).

[4] Updegraff D.M. (1969). Semi-micro determination of cellulose in biological materials in Anal. Biochem. (pp. 420-424).

[5] Varghese K.S., Pandey M.C., Radhakrishna K. and Bawa A.S. (2014). Technology, applications and modelling of ohmic heating: a review in J. Food Sci. Technol. (pp.2304-2317).

[6] Wang F., Wang Y. A and Ji M. (2005) Mechanisms and kinetics models for ultrasonic waste activated sludge disintegration. J. Hazard. Mater. ( pp. 145-150).

[7] Yuan H., Yan X., Yang C. and Zhua, N. (2011) Enhancement of waste activated sludge dewaterability by electro-chemical pretreatment in J. Hazard. Mater. (pp. 82-88).

[8] Zhen G., Lu X., Li Y., and Zhao Y. (2014) Combined electrical-alkali pretreatment to increase the anaerobic hydrolysis rate of waste in Applied Energy (pp. 93-102) 